\title{
Cephalometric association of mandibular size/length to the surface area and dimensions of the frontal and maxillary sinuses
}

\author{
Soghra Yassaei $^{1}$, Akramsadat Emami $^{2}$, Sanam Mirbeigi ${ }^{3}$
}

Correspondence: Dr. Akramsadat Emami

Email: emami.a93@gmail.com

\begin{abstract}
'Department of Orthodontics, Faculty of Dentistry, Shahid Sadoughi University of Medical Sciences, Yazd, Iran,

Faculty of dentistry, Shahid Sadoughi University of Medical Sciences, Yazd, Iran,

${ }^{3}$ Department of Oral and Maxillofacial Radiology, Faculty of Dentistry, Shahid Sadoughi University of Medical Sciences, Yazd, Iran
\end{abstract}

\section{ABSTRACT}

Objective: This study aimed to determine the cephalometric association of mandibular size/length to the surface area and dimensions of the frontal and maxillary sinuses. Materials and Methods: This descriptive study was conducted on 116 digital lateral cephalograms of 38 patients with skeletal Class I malocclusion (normal), 40 patients with skeletal Class II malocclusion with mandibular deficiency, and 38 patients with skeletal Class III malocclusion with mandibular excess. Both male and female patients were included. Using AutoCAD 2016 software, the anteroposterior dimension, height and surface area of the frontal and maxillary sinuses, mandibular body length and cephalometric indices including anterior and posterior cranial bases, and growth pattern indices were measured on lateral cephalograms. Results: Dimensions and surface area of the frontal and maxillary sinuses in skeletal Class III malocclusion were greater than those in other groups. These variables were significantly correlated with the mandibular body length. The coefficient for the correlation of height, width, and surface area of the frontal sinus with mandibular body length was $0.253,0.284$, and 0.490 , respectively. The coefficient for the correlation of height, length, and surface area of the maxillary sinus with mandibular body length was $0.346,0.657$, and 0.661 , respectively. These variables (except for the frontal sinus width) had a significant correlation with the anterior and posterior cranial bases. The frontal sinus width had a significant correlation with the anterior cranial base. These variables in males were greater than those in females. Conclusion: The dimensions and surface area of the frontal and maxillary sinuses in skeletal Class III malocclusion were greater than those in other groups. These variables (except for the frontal sinus width) had a significant correlation with the anterior and posterior cranial bases and mandibular body length.

Key words: Frontal sinus, maxillary sinuses, skeletal malocclusion

\section{INTRODUCTION}

Paranasal sinuses are bony chambers surrounding the nasal cavity. ${ }^{[1]}$ The frontal sinus is a cavity in the frontal bone and is one of the paranasal sinuses. ${ }^{[2]}$

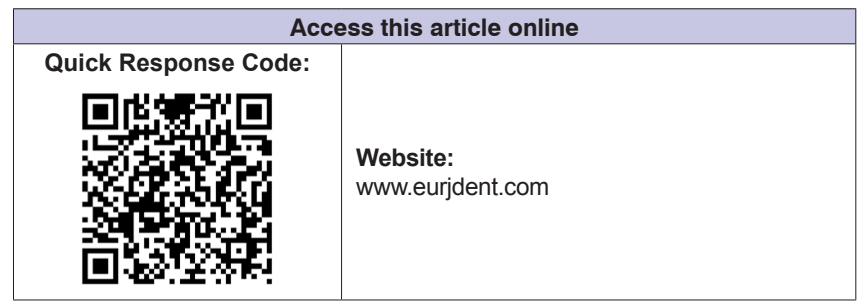

Its shape and size are influenced by race, gender, bioenvironmental factors, diseases, and growth pattern. ${ }^{[3]}$ This sinus is very small or nonexistent at

This is an open access journal, and articles are distributed under the terms of the Creative Commons Attribution-NonCommercial-ShareAlike 4.0 License, which allows others to remix, tweak, and build upon the work non-commercially, as long as appropriate credit is given and the new creations are licensed under the identical terms.

For reprints contact: reprints@medknow.com

How to cite this article: Yassaei S, Emami A, Mirbeigi S. Cephalometric association of mandibular size/length to the surface area and dimensions of the frontal and maxillary sinuses. Eur J Dent 2018;12:253-61.

DOI: 10.4103/ejd.ejd_345_17 
birth. ${ }^{[4]}$ Vertical growth of the sinus starts at 2 years of age and it is visible on cephalograms at the age of 8 . The growth peak of the frontal sinus occurs at about 1 year after the growth peak of the body. ${ }^{[5]}$ Brown et al. noticed that the main part of the growth of the frontal sinus stops at the age of 15.5 years in boys and 13 - years in girls. ${ }^{[6]}$

The maxillary sinus is the largest sinus among the paranasal sinuses. ${ }^{[7]}$ Its development starts at the $3^{\text {rd }}$ month of fetal development from the infundibulum of the ethmoid bone. ${ }^{[8]}$ After birth, it continues to expand laterally during the two growth spurt periods (from birth to 3 years of age and from 7 to 12 years). ${ }^{[9]}$

However, the mandibular growth continues well after the latter ages and reaches its final dimensions at about the age of 20 years in males and 18 years in females. ${ }^{[10]}$ Since the normal mandibular growth can cause treatment failure in Class III malocclusion patients, estimating the exact final size of the jaw in these patients is important. ${ }^{[11]}$ Accurate timing for treatment of Class II and Class III skeletal malocclusions significantly affects the success of orthodontic treatment. ${ }^{[12]}$ Rossouw et al. reported that the frontal sinus surface area may be used as an index for mandibular growth prediction. ${ }^{[11]}$ Salehi et al. evaluated 71 lateral cephalograms of adult patients and concluded that the frontal sinus surface area may play a role in the final size of the mandible. ${ }^{[10]}$

Given that a direct correlation exists between the surface area and dimensions of the frontal and maxillary sinuses with the mandibular body growth, dimensions and surface area of the frontal and maxillary sinuses can be used to estimate the residual mandibular growth. Thus, we aimed to determine the cephalometric association of mandibular size/length to the surface area and dimensions of the frontal and maxillary sinuses.

\section{MATERIALS AND METHODS}

This descriptive study was conducted on lateral cephalograms of patients presenting to the Orthodontics Department of Faculty of Dentistry, Shahid Sadoughi University of Medical Sciences, Yazd, Iran. All the cephalograms were taken at the Radiology Department of the Faculty of Dentistry with a Planmeca ProMax ${ }^{\circledR}$ machine (Helsinki, Finland) with exposure settings of $12 \mathrm{~mA}, 80 \mathrm{kVp}$, and $15 \mathrm{~s}$, under standard conditions (patients in centric occlusion and natural head position).
Lateral cephalograms were divided into skeletal Class I (normal) $(1<\mathrm{ANB} \leq 4,-1 \leq$ Wits $\leq 0)$, skeletal Class II (ANB $>4$, Wits $>0$ ), and Class III (ANB $\leq 1$, Wits $<-1$ ) malocclusions according to the ANB angle and Wits appraisal. If the mandibular plane angle (GoGn to SN) was higher or lower than the mean of $32^{\circ}\left( \pm 5^{\circ}\right)$, the ANB was a reliable indication of anteroposterior jaw discrepancy and if the mandibular plane angle was $>37^{\circ}$ or $<27^{\circ}$, the Wits appraisal was valuable for accurately assessing the severity of anteroposterior jaw discrepancy. ${ }^{[13]}$ In Class II and Class III skeletal malocclusions, the mandibular body length was calculated ideally according to the Schwartz index (SeN $+3 \mathrm{~mm}=$ body length) (Se: midpoint of entrance to the Sella, N: Nasion, the most anterior point of the frontonasal suture $)^{[14,15]}$ and was compared with the mandibular body length of patients. In Class II malocclusion, if the mandibular body length was smaller than the obtained value, the patient was diagnosed with mandibular deficiency. If the value was equal or larger than the ideal value, the patient was excluded from the study. In Class III malocclusion patients, if the mandibular body length was larger than the obtained value, the patient was diagnosed with mandibular excess. If the value was equal or smaller than the ideal size, the patient was excluded from the study. Thus, 38 Class I, 40 Class II, and 38 Class III malocclusion patients were enrolled in this study.

Lateral cephalograms of the following patients were included in this study (inclusion criteria):

- Age range of 15-20 years

- No syndrome or cleft lip and palate

- No history of previous orthodontic treatment or maxillofacial surgery

- No frontal or maxillary sinus pathology

- Malocclusions associated with mandibular discrepancy such as Class III malocclusion with mandibular excess and Class II malocclusion with mandibular deficiency.

The exclusion criteria were:

Poor-quality images on which frontal and maxillary sinuses could not be well visualized and absence of digital film of cephalogram.

The definition of assessed cephalometric indices in this study is presented in Table 1.

\section{Sample size}

Sample size was calculated according to $95 \%$ confidence level, standard deviation of 3 (for MSH, MSL), and 


\begin{tabular}{ll} 
Table 1: Definition of assessed cephalometric indices \\
\hline Index & Definition \\
\hline SN & Anterior cranial base length \\
AR-S & Posterior cranial base length \\
Mandibular body length & Distance from Go to Gn \\
SN-GoGn angle & Angle between anterior cranial base and GoGn \\
Jarabak index & Posterior facial height (S-Go) to anterior facial height (N-Me) ratio (\%) \\
Sum of posterior angles & Sum of saddle, articular, and gonial angles \\
Gonial angle & Intersection of the lines tangent to the posterior border of the ramus and the lower border of mandible \\
ANB & Anteroposterior relationship between A-point and B-point with respect to nasion \\
Wits & Distance between the points of contact of the perpendicular lines on the occlusal \\
& plane (AO: A point to occlusal plane and BO: B point to occlusal plane) \\
Occlusal plane & Line drawn through the overlap of the mesiobuccal cusps of the first molars and the buccal cusps of the first \\
& premolars
\end{tabular}

estimated error of 0.6 . So, 111 samples were needed. Thus, our sample size was large enough to detect statistically meaningful equivalence for this study.

\section{Measuring sinus dimensions}

Lateral cephalograms were entered into AutoCAD 2016 software (Autodesk Inc., San Rafael, CA, USA) and the sinuses were outlined by an experienced operator using AutoCAD software features. Since the external borders of the sinuses are visualized as white bands, which are thick in some areas, the internal surface of the opaque wall was considered as the sinus border. In areas of the sinus where two opaque walls were seen next to each other, a hypothetical line between these walls was considered as the border of the sinus.

The frontal sinus indices were assessed as follows:

- Height of the frontal sinus: A line was drawn from $\mathrm{SH}$ to SL (SH: the highest point, SL: the lowest point $)^{[5]}$

- Width of the frontal sinus: It was determined by connecting SPP and SAP points (SPP: most posterior point of the sinus, SAP: most anterior point of the sinus) ${ }^{[5]}$

- Ratio of height to width of the frontal sinus ${ }^{[2]}$

- Surface area of the frontal sinus: The outlined surface area was calculated. ${ }^{[10]}$

The maxillary sinus indices were assessed as follows: ${ }^{[16]}$

- Maxillary sinus height: A line was drawn from Su to In (Su: the highest point, In: the lowest point)

- Maxillary sinus length: A line was drawn from An to Po (An: the most anterior point, Po: the most posterior point)

- Maxillary sinus surface area: The surface area of the outlined sinus was calculated.

In addition to the surface area and dimensions of the frontal and maxillary sinuses, growth pattern indices, lines connecting the anterior and posterior cranial bases and the mandibular body length, were measured in AutoCAD software.

In all the radiographs, the graded forehead support was considered as an index of homogeneity. In AutoCAD, lines were measured in millimeters, surface area was measured in square millimeters, and the angles were measured in degrees. All measurements were made by the same operator [Figures 1 and 2]. All measurements were repeated after 1 week by the same operator to ensure intra-examiner reliability, and the mean of each index was then calculated. All the measured values were entered into Excel software.

\section{Statistical analysis}

Mean and standard deviation were calculated for each parameter. Normal distribution of data was confirmed by Kolmogorov-Smirnov test $(P>0.05)$. Therefore, Student's $t$-test for independent samples was used to compare sinus dimensions between males and females. ANOVA, followed by post hoc Tukey's tests, was used to compare the differences among the three groups. The relationship between sinus dimensions and cephalometric indices was assessed by the Pearson's correlation coefficient. All statistical analyses were performed using SPSS version 21 software (SPSS Inc., IL, USA). $P<0.05$ was defined to be statistically significant for all the tests.

\section{RESULTS}

Tables 2 and 3 report the mean surface area of the frontal sinus in Class III malocclusion which was significantly greater than that in the other two groups $(P=0.0001)$. In addition, the mean height and width of the frontal sinus in Class III malocclusion were significantly greater than those in the other two groups $(P<0.05)$. The mean ratio of the height to width 
of the frontal sinus was not significantly different among the three groups $(P=0.299)$ [Figures 3 and 4 ].

The mean height of the maxillary sinus in skeletal Class III malocclusion was significantly higher than that in Class II and Class I malocclusions $(P=0.006)$. Maxillary sinus length in Class III malocclusion was significantly greater than that in the other two groups, but this difference was not statistically

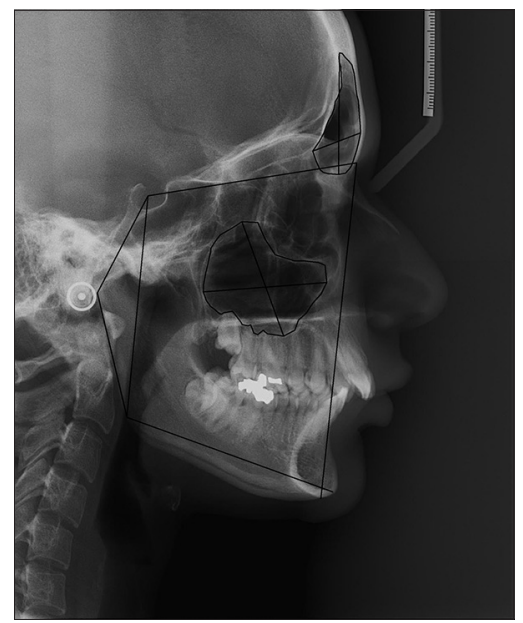

Figure 1: Lateral cephalometric image with measurements done on AutoCAD software

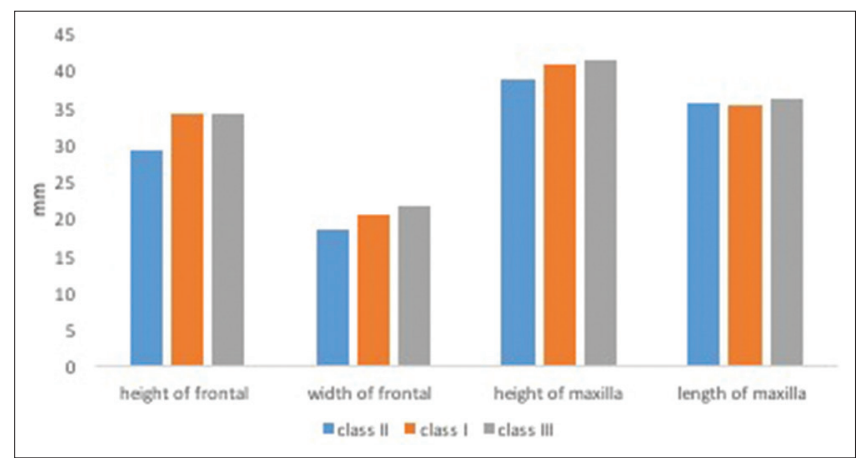

Figure 3: Comparison of the mean height and width of the frontal and maxillary sinuses in Class I, II, and III malocclusions significant $(P=0.501)$. The mean surface area of the maxillary sinus in Class III skeletal malocclusion was greater than that in the other two groups and this difference was statistically significant $(P=0.001)$ [Tables 2, 3 and Figures 3, 4].

According to Tables 4 and 5, comparison of males and females revealed that all variables under study (except for the height-to-width ratio of the frontal sinus) in males were greater than those in

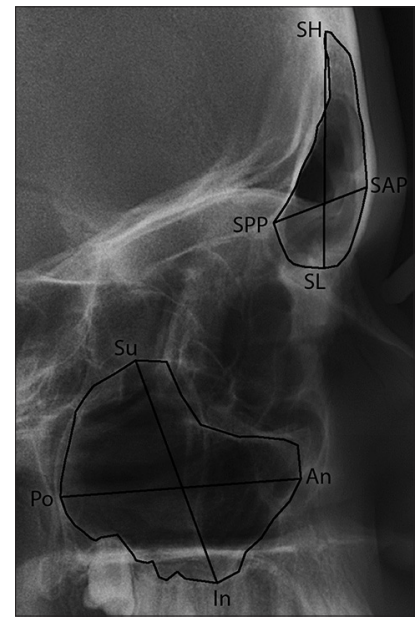

Figure 2: Frontal and maxillary sinuses measurement on the lateral cephalograms in AutoCAD software

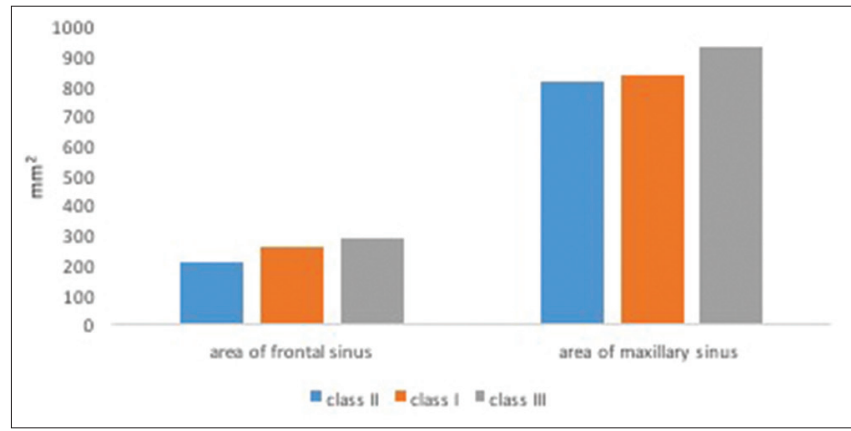

Figure 4: Comparison of the mean surface area of the frontal and maxillary sinuses in Class I, II, and III malocclusions

\begin{tabular}{|c|c|c|c|c|c|c|c|}
\hline \multirow[t]{3}{*}{ Variables } & \multicolumn{6}{|c|}{ Groups } & \multirow[t]{3}{*}{$P$ (ANOVA) } \\
\hline & \multicolumn{2}{|c|}{ Class II } & \multicolumn{2}{|c|}{ Class III } & \multicolumn{2}{|c|}{ Class I } & \\
\hline & Mean & SD & Mean & SD & Mean & SD & \\
\hline Frontal sinus height & 29.12 & 5.182 & 34.14 & 4.127 & 34.1 & 6.270 & $0.0001^{*}$ \\
\hline Frontal sinus width & 18.31 & 4.268 & 21.44 & 3.068 & 20.25 & 4.105 & $0.002^{*}$ \\
\hline Frontal sinus surface area & 207.88 & 78.271 & 283.66 & 74.694 & 256.19 & 87.951 & $0.0001^{*}$ \\
\hline Ratio of height to width of the frontal sinus (\%) & 164.35 & 35.354 & 160.74 & 27.519 & 172.29 & 35.425 & 0.299 \\
\hline Maxillary sinus height & 38.56 & 4.094 & 41.38 & 4.260 & 40.78 & 3.707 & $0.006^{*}$ \\
\hline Maxillary sinus length & 35.48 & 4.073 & 36.03 & 3.522 & 35.02 & 3.668 & 0.501 \\
\hline Maxillary sinus surface area & 812.91 & 125.816 & 928.01 & 133.969 & 836.26 & 139.582 & $0.001^{*}$ \\
\hline
\end{tabular}




\begin{tabular}{|c|c|c|c|c|c|c|}
\hline \multirow[t]{3}{*}{ Variables } & \multicolumn{6}{|c|}{ Groups } \\
\hline & \multicolumn{2}{|l|}{ Class II } & \multicolumn{2}{|l|}{ Class III } & \multicolumn{2}{|l|}{ Class I } \\
\hline & Difference in mean & $P$ & Difference in mean & $P$ & Difference in mean & $P$ \\
\hline \multicolumn{7}{|c|}{ Frontal sinus height } \\
\hline Class II & & & -5.01 & $0.0001^{*}$ & -4.97 & $0.0001^{*}$ \\
\hline Class III & 5.01 & $0.0001^{*}$ & & & 0.04 & 1.000 \\
\hline Class I & 4.97 & $0.0001^{*}$ & -0.04 & 1.000 & & \\
\hline \multicolumn{7}{|c|}{ Frontal sinus width } \\
\hline Class II & & & -3.13 & $0.002^{*}$ & -1.94 & 0.086 \\
\hline Class III & 3.13 & $0.002^{*}$ & & & 1.19 & 0.539 \\
\hline Class I & 1.94 & 0.086 & -1.19 & 0.539 & & \\
\hline \multicolumn{7}{|c|}{ Frontal sinus surface area } \\
\hline Class II & & & -75.78 & $0.0001^{*}$ & -48.31 & $0.028^{*}$ \\
\hline Class III & 75.78 & $0.0001^{*}$ & & & 27.46 & 0.419 \\
\hline Class I & 48.31 & 0.028 & -27.46 & 0.419 & & \\
\hline \multicolumn{7}{|c|}{$\begin{array}{l}\text { Ratio of height to width of } \\
\text { the frontal sinus (\%) }\end{array}$} \\
\hline Class II & & & 3.61 & 1.000 & -7.94 & 0.872 \\
\hline Class III & -3.61 & 1.000 & & & -11.55 & 0.390 \\
\hline Class I & 7.94 & 0.872 & 11.55 & 0.390 & & \\
\hline \multicolumn{7}{|c|}{ Maxillary sinus height } \\
\hline Class II & & & -2.82 & $0.008^{*}$ & -2.22 & $0.050^{*}$ \\
\hline Class III & 2.82 & $0.008^{*}$ & & & 0.60 & 1.000 \\
\hline Class I & 2.22 & $0.050^{*}$ & -0.60 & 1.000 & & \\
\hline \multicolumn{7}{|c|}{ Maxillary sinus length } \\
\hline Class II & & & -0.55 & 1.000 & 0.46 & 1.000 \\
\hline Class III & 0.55 & 1.000 & & & 1.02 & 0.724 \\
\hline Class I & -0.46 & 1.000 & -1.02 & 0.724 & & \\
\hline \multicolumn{7}{|c|}{ Maxillary sinus surface area } \\
\hline Class II & & & -115.11 & $0.001^{*}$ & -23.35 & 1.000 \\
\hline Class III & 115.11 & $0.001^{*}$ & & & 91.75 & $0.010^{*}$ \\
\hline Class I & 23.35 & 1.000 & -91.75 & $0.010^{*}$ & & \\
\hline
\end{tabular}

\begin{tabular}{|c|c|c|c|c|c|c|c|c|}
\hline & \multicolumn{8}{|c|}{ Frontal sinus } \\
\hline & \multicolumn{2}{|c|}{ Height } & \multicolumn{2}{|c|}{ Width } & \multicolumn{2}{|c|}{ Area } & \multicolumn{2}{|c|}{ Height/width (\%) } \\
\hline & Female & Male & Female & Male & Female & Male & Female & Male \\
\hline Mean & 31.69 & 33.125 & 19.48 & 20.48 & 216.39 & 281.80 & 166.56 & 164.95 \\
\hline SD & 5.176 & 6.229 & 4.039 & 4.014 & 67.023 & 90.853 & 30.368 & 35.930 \\
\hline$P$ & \multicolumn{2}{|c|}{0.180} & \multicolumn{2}{|c|}{0.184} & \multicolumn{2}{|c|}{$0.0001^{*}$} & \multicolumn{2}{|c|}{0.794} \\
\hline
\end{tabular}

females; however, only the difference in the frontal sinus surface area and height, length, and surface area of the maxillary sinus was statistically significant $(P<0.05)$ [Figure 5].

The height and surface area of the frontal sinus were significantly correlated with the linear size of ArS, SN, and the mandibular body length such that the larger the frontal sinus, the greater were the linear values. The frontal sinus width had a significant correlation with the linear size of SN and mandibular body length [Table 6]. Furthermore, a significant correlation was noted between the dimensions and surface area of the maxillary sinus and the linear size of SN, ArS, and the mandibular length [Table 7].

Based on the results of this study, a significant inverse correlation was noted between the length and surface area of the maxillary sinus and the GoGn-Sn angle and the sum of posterior angles such that by an increase in size of these angles, the length and surface area of the maxillary sinus decreased [Table 7]. 
Tables 6 and 7 report the dimensions and surface area of the frontal sinus, and the height of the maxillary sinus showed a significant correlation with the gonial angle such that these variables increased by an increase in gonial angle.

Only the surface area of the maxillary sinus had a significant correlation with the Jarabak index, and other dimensions of the sinus did not have a significant correlation with this index $(P>0.05)$ [Tables 6 and 7].

Multiple regression analysis was used to assess the correlation of mandibular body length with frontal and maxillary sinus parameters.

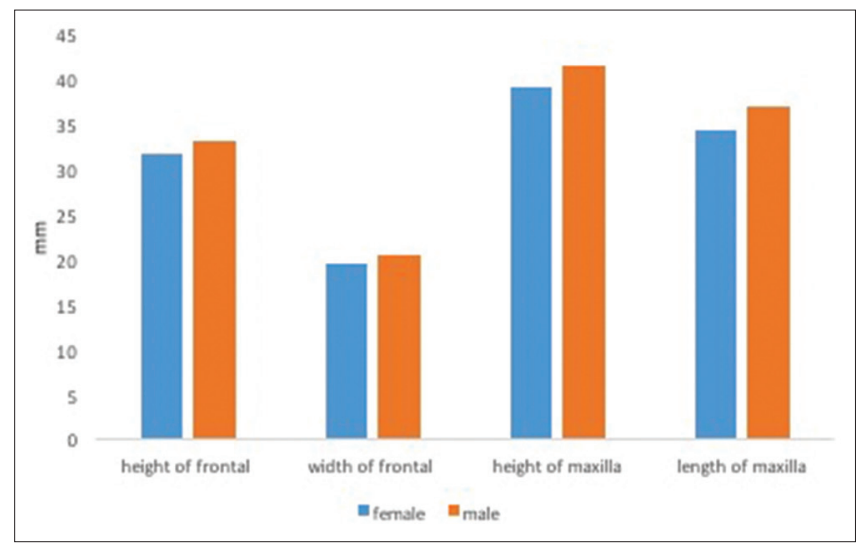

Figure 5: Comparison of the mean dimensions of the frontal and maxillary sinuses in males and females

\begin{tabular}{|c|c|c|c|c|c|c|}
\hline & \multicolumn{6}{|c|}{ Maxillary sinus } \\
\hline & \multicolumn{2}{|c|}{ Height } & \multicolumn{2}{|c|}{ Length } & \multicolumn{2}{|c|}{ Area } \\
\hline & Female & Male & Female & Male & Female & Male \\
\hline Mean & 39.03 & 41.44 & 34.18 & 36.88 & 802.53 & 915.95 \\
\hline SD & 3.645 & 4.367 & 3.423 & 3.616 & 116.762 & 141.685 \\
\hline$P$ & \multicolumn{2}{|c|}{$0.002^{*}$} & \multicolumn{2}{|c|}{$0.0001^{*}$} & \multicolumn{2}{|c|}{$0.0001^{*}$} \\
\hline
\end{tabular}

$T$-test. ${ }^{*} P<0.05 . \mathrm{SD}:$ Standard deviation
As shown in Table 8, changes in the mandibular body length were estimated with $52.5 \%$ probability using the following formula:

Mandibular body length $=31.253-0.210$ (frontal sinus height) +0.004 (frontal sinus width) +0.020 (frontal sinus surface area) -0.110 (maxillary sinus height) +0.692 (maxillary sinus length) +0.020 (maxillary sinus surface area)

\section{DISCUSSION}

Lateral cephalometry is often requested as a necessary record for orthodontic diagnosis and assessment of treatment results. Stability of the results of orthodontic treatment is a concern for many orthodontists. Final size of the mandible is one of the most important factors affecting the treatment outcome. This is particularly important in patients with Class III malocclusion. ${ }^{[1]}$ Limited studies have assessed the size of frontal and maxillary sinuses in different malocclusions. ${ }^{[9,16,17]}$ The current study aimed to assess the correlation of frontal sinus and maxillary sinus parameters with the mandibular body length and craniofacial structures on lateral cephalograms.

In the current study, digital lateral cephalograms and AutoCAD software were used for assessment of the dimensions of the frontal and maxillary sinuses and their surface area. Digital lateral cephalometry provides high-quality images; thus, errors in localization of landmarks are minimized.

AutoCAD is one of the most commonly used software programs for 2D and 3D computer-aided designs. It was first introduced by AutoDesk company in 1982 for professional designing. ${ }^{[18]}$ AutoCAD 2016 was used in this study, which enabled us to accurately outline the sinuses and calculate their surface area.

\begin{tabular}{|c|c|c|c|c|c|c|c|c|}
\hline & \multicolumn{8}{|c|}{ Frontal sinus } \\
\hline & \multicolumn{2}{|c|}{ Height } & \multicolumn{2}{|c|}{ Width } & \multicolumn{2}{|c|}{ Surface area } & \multicolumn{2}{|c|}{ Height/width } \\
\hline & $\boldsymbol{R}$ & $P$ & $\boldsymbol{R}$ & $P$ & $R$ & $P$ & $R$ & $P$ \\
\hline SN & 0.209 & $0.024^{*}$ & 0.246 & $0.008^{*}$ & 0.453 & $0.0001^{*}$ & -0.099 & 0.289 \\
\hline AR-S & 0.230 & $0.013^{*}$ & 0.084 & 0.371 & 0.430 & $0.0001^{*}$ & 0.094 & 0.318 \\
\hline Mandibular body length & 0.253 & $0.006^{*}$ & 0.284 & $0.002^{*}$ & 0.490 & $0.0001^{*}$ & -0.111 & 0.235 \\
\hline SN-GoGn angle & 0.024 & 0.797 & 0.014 & 0.879 & -0.165 & 0.077 & 0.032 & 0.735 \\
\hline Jarabak index & -0.034 & 0.720 & -0.088 & 0.348 & 0.089 & 0.344 & 0.040 & 0.668 \\
\hline Sum of posterior angles & 0.035 & 0.710 & 0.022 & 0.813 & -0.155 & 0.097 & 0.032 & 0.736 \\
\hline Gonial angle & 0.185 & $0.047^{*}$ & 0.232 & $0.012^{*}$ & 0.207 & $0.026^{*}$ & -0.090 & 0.337 \\
\hline
\end{tabular}




\begin{tabular}{|c|c|c|c|c|c|c|}
\hline & \multicolumn{6}{|c|}{ Maxillary sinus } \\
\hline & \multicolumn{2}{|c|}{ Height } & \multicolumn{2}{|c|}{ Length } & \multicolumn{2}{|c|}{ Surface area } \\
\hline & $R$ & $P$ & $R$ & $P$ & $R$ & $P$ \\
\hline SN & 0.208 & $0.025^{*}$ & 0.735 & $0.0001^{*}$ & 0.621 & $0.0001^{*}$ \\
\hline AR-S & 0.320 & $0.0001^{*}$ & 0.374 & $0.0001^{*}$ & 0.418 & $0.0001^{*}$ \\
\hline $\begin{array}{l}\text { Mandibular } \\
\text { body length }\end{array}$ & 0.346 & $0.0001^{*}$ & 0.657 & $0.0001^{*}$ & 0.661 & $0.0001^{*}$ \\
\hline $\begin{array}{l}\text { SN-GoGn } \\
\text { angle }\end{array}$ & -0.071 & 0.447 & -0.376 & $0.0001^{*}$ & -0.307 & $0.001^{*}$ \\
\hline Jarabak index & 0.136 & 0.144 & 0.165 & 0.077 & 0.175 & $0.05^{*}$ \\
\hline $\begin{array}{l}\text { Sum of } \\
\text { posterior } \\
\text { angles }\end{array}$ & -0.076 & 0.418 & -0.368 & $0.0001^{*}$ & -0.302 & $0.001^{*}$ \\
\hline Gonial angle & 0.182 & $0.050^{*}$ & -0.146 & 0.119 & 0.047 & 0.617 \\
\hline
\end{tabular}

\begin{tabular}{|c|c|c|}
\hline Independent variable & Regression coefficient & $\boldsymbol{P}$ \\
\hline Width from reference & 31.253 & 0.0001 \\
\hline Frontal sinus height & -0.210 & 0.132 \\
\hline Frontal sinus width & 0.004 & 0.978 \\
\hline Frontal sinus surface area & 0.020 & 0.073 \\
\hline Maxillary sinus height & -0.110 & 0.505 \\
\hline Maxillary sinus length & 0.692 & 0.001 \\
\hline Maxillary sinus surface area & 0.020 & 0.008 \\
\hline
\end{tabular}

The current results showed that the mean height, width, and surface area of the frontal sinus in Class III skeletal malocclusion were significantly greater than those in Class I and II malocclusions. Furthermore, the dimensions and surface area of the frontal sinus had a significant correlation with the mandibular body length and gonial angle. Rossouw et al. and also Salehi et al. reported that the surface area of the frontal sinus may play a role in the final size of the mandible and they found a significant correlation between the size of the frontal sinus and mandibular body length. ${ }^{[10,11]}$

The results of our study showed that the mean height, width, and surface area of the frontal sinus in males were greater than those in females, but the ratio of height to width of the frontal sinus in females was greater than that in males; this difference was only significant for the frontal sinus surface area.

Kiran et al. showed that the mean height and width of the frontal sinus were significantly greater in males, while the ratio of height to width of the frontal sinus in females was significantly higher than that in males. ${ }^{[2]}$ This finding was in line with the current results. However, in our study, this difference did not reach statistical significance, which may be due to our small sample size.

Tehranchi et al. showed that the mean height, width, and surface area of the frontal sinus on lateral cephalograms in males were greater than those in females, ${ }^{[19]}$ which was in agreement with the current findings. However, in our study, only the difference in frontal sinus surface area reached statistical significance. This difference between the results of the two studies may be attributed to the fact that Tehranchi et al. ${ }^{[19]}$ assessed lateral cephalograms of patients older than 12 years of age, while we evaluated patients in the age range of 15-20 years. In this age range, frontal sinus almost reaches its final size. ${ }^{[6]}$

Genetics and growth pattern of the maxillofacial structures are two important factors affecting the dimensions of the frontal sinus. ${ }^{[20]}$ The current study assessed the correlation of cephalometric indices and dimensions of the frontal sinus in an Iranian population. The results showed that the mean height and surface area of the frontal sinus had a significant correlation with linear distances of SN and ArS. Thus, patients with larger anterior or posterior cranial base have a larger frontal sinus. Dimensions and surface area of the frontal sinus had no significant correlation with vertical dimensions of the face such as the sum of posterior angles, SN-GoGn, and the Jarabak index.

The current results showed that the height and surface area of the maxillary sinus in skeletal Class III malocclusion were significantly greater than those in Class I and Class II malocclusions. Furthermore, the mean anteroposterior length in Class III patients was greater than that in the other two groups, but this difference was not significant. Endo et al. reported that the height of the maxillary sinus in males was greater in Class III malocclusion compared to other malocclusions, ${ }^{[16]}$ which was in accordance with our findings. However, this difference was statistically significant in our study. The reason may be the fact that Endo et al. ${ }^{[16]}$ evaluated lateral cephalograms of patients aged between 12 and 16 years.

Oktay $^{[1]}$ and Urabi and Al-Nakib ${ }^{[9]}$ found no significant correlation between the size of the sinus and malocclusion, which was not in line with our results. The difference between our results and those of Oktay, ${ }^{[1]}$ Urabi and Al-Nakib, ${ }^{[9]}$ and Endo et al. ${ }^{[16]}$ was probably due to the fact that we classified patients according to the small and large size of the mandible, while classification in other studies was mainly based 
on the ANB angle. The current results showed a significant correlation between height, length, and surface area of the maxillary sinus with SN and ArS linear distances. The greater the anterior or posterior cranial base, the larger the maxillary sinus wound be. The same finding was also reported by Endo et al., ${ }^{[16]}$ Hopkin et al., ${ }^{[21]}$ and Dibbets. ${ }^{[22]}$

According to our results as well as those of Jalal, ${ }^{[23]}$ Al-Azzawi, ${ }^{[17]}$ Hopkin et al., ${ }^{[21]}$ and Dibbets, ${ }^{[22]}$ dimensions and surface area of the maxillary sinus were significantly greater in males than females. Since the skull base in males was larger than that in females and individuals with a larger cranial base have a larger maxillary sinus, males have a larger maxillary sinus than females.

According to our findings, height, length, and surface area of the maxillary sinus were correlated with the mandibular body length. This shows that increase in length and surface area of the maxillary sinus is associated with a larger mandible in $36 \%$ of the cases. Furthermore, height of the maxillary sinus had a significant correlation with gonial angle such that the maxillary sinus height was greater in patients with a larger gonial angle.

Assessment of the angles determining the facial growth pattern (SN-GoGn angle, Jarabak index, and sum of posterior angle) and their correlation with length and surface area of the maxillary sinus revealed that length and surface area of the maxillary sinuses were smaller in patients with a vertical facial growth pattern and patients with a longer face had maxillary sinuses with a smaller length and surface area.

In our study, multiple linear regression analysis was used to analyze the correlation of mandibular body length with frontal and maxillary sinus indices and showed that changes in the mandibular body length can be predicted using the following formula with $52.5 \%$ probability:

Mandibular body length $=31.253-0.210$ (frontal sinus height) +0.004 (frontal sinus width) +0.020 (frontal sinus surface area) - 0.110 (maxillary sinus height) +0.692 (maxillary length) +0.020 (maxillary sinus surface area).

This formula can be used to predict ultimate mandibular size in Class III malocclusion patients and how they grow in the future. Thus, with the dimensions and surface area of the frontal and maxillary sinuses, it can be determined that whether patient needs orthosurgery treatment after puberty or can be treated with orthodontic camouflage.

In order to increase the accuracy of the study, it is suggested that in future studies, dimensions, surface area, and volume of sinuses in different occlusions should be evaluated by cone-beam computed tomography.

\section{CONCLUSION}

According to the results of this study, the following conclusions may be drawn:

1. Dimensions and surface area of the frontal and maxillary sinuses in skeletal Class III malocclusion were greater than those in other types of malocclusions (Class I and II malocclusions); however, the difference with regard to the length of the maxillary sinus was not statistically significant

2. Dimensions and surface area of the frontal and maxillary sinuses (except for the frontal sinus width) had a significant correlation with the mandibular body length and the anterior and posterior cranial bases. Frontal sinus width had a significant correlation with the mandibular body length and the anterior cranial base

3. Dimensions and surface area of the sinuses in males were greater than those in females; however, only the difference with regard to the frontal sinus surface area and dimensions and surface area of the maxillary sinuses were statistically significant.

\section{Financial support and sponsorship}

Nil.

\section{Conflicts of interest}

There are no conflicts of interest.

\section{REFERENCES}

1. Oktay H. The study of the maxillary sinus areas in different orthodontic malocclusions. Am J Orthod Dentofacial Orthop 1992;102:143-5.

2. Kiran CS, Ramaswamy P, Khaitan T. Frontal sinus index - A new tool for sex determination. J Forensic Radiol Imaging 2014;2:77-9.

3. Akhlaghi M, Bakhtavar K, Moarefdoost J, Kamali A, Rafeifar S. Frontal sinus parameters in computed tomography and sex determination. Leg Med (Tokyo) 2016;19:22-7.

4. Goyal M, Acharya AB, Sattur AP, Naikmasur VG. Are frontal sinuses useful indicators of sex? J Forensic Leg Med 2013;20:91-4.

5. Guevara YV, Watanabe N, Yamaki M, Saito I. The frontal sinus enlargement as an indicator of growth maturity in class III patients - A pilot study. Int J Med Sci Public Health 2013;2:451-5.

6. Brown WA, Molleson TI, Chinn S. Enlargement of the frontal sinus. Ann Hum Biol 1984;11:221-6.

7. Emirzeoglu M, Sahin B, Bilgic S, Celebi M, Uzun A. Volumetric evaluation of the paranasal sinuses in normal subjects using computer tomography images: A stereological study. Auris Nasus Larynx 2007;34:191-5.

8. Scuderi AJ, Harnsberger HR, Boyer RS. Pneumatization of the 
paranasal sinuses: Normal features of importance to the accurate interpretation of CT scans and MR images. AJR Am J Roentgenol 1993;160:1101-4.

9. Urabi AH, Al-Nakib LH. Digital lateral cephalometric assessment of maxillary sinus dimensions in different skeletal classes. J Univ Baghdad 2012;24:35-8.

10. Salehi P, Heidari S, Khajeh F. Relationship between frontal sinus surface area and mandibular size on lateral cephalograms of adults. J Isfahan Dent Sch 2012;8:244-50.

11. Rossouw PE, Lombard CJ, Harris AM. The frontal sinus and mandibular growth prediction. Am J Orthod Dentofac Orthop 1991;100:542-6.

12. Lambrechts AH, Harris AM, Rossouw PE, Stander I. Dimensional differences in the craniofacial morphologies of groups with deep and shallow mandibular antegonial notching. Angle Orthod 1996;66:265-72.

13. Jacobson A. Radiographic Cephalometry: From Basics to Video Imaging. Chicago, Carol Stream, IL: Quintessence Publishing; 1995. p. 97-112.

14. Rakosi T, Jonas I, Graber TM. Orthodontic Diagnosis. Foreword by Moyers RE. Stuttgart, New York: G. Thieme Verlag, Thieme Medical Publishers Inc.; 1993. p. 186.

15. Yassaei S, Sorush M. Changes in hyoid position following treatment of class II division1 malocclusions with a functional appliance. J Clin Pediatr Dent 2008;33:81-4.

16. Endo T, Abe R, Kuroki H, Kojima K, Oka K, Shimooka S, et al. Cephalometric evaluation of maxillary sinus sizes in different malocclusion classes. Odontology 2010;98:65-72.

17. Al-Azzawi AM. Maxillary sinus area in both gender and its relation to skeletal class III malocclusion. Med J Babylon 2013;10:508-16.

18. Watson RW, Myer TH, Sutherland IE, Vosbury MK. A display processor design. FJCC 1969;35:209-17.

19. Tehranchi A, Motamedian SR, Saedi S, Kabiri S, Shidfar S. Correlation between frontal sinus dimensions and cephalometric indices: A cross-sectional study. Eur J Dent 2017;11:64-70.

20. Szilvássy J. Development of the frontal sinuses. Anthropol Anz 1981;39:138-49.

21. Hopkin GB, Houston WJ, James GA. The cranial base as an aetiological factor in malocclusion. Angle Orthod 1968;38:250-5.

22. Dibbets JM. Morphological associations between the angle classes. Eur J Orthod 1996;18:111-8.

23. Jalal FA. Estimation of Gender and Age Using Spiral CT Scanning of Maxillary Sinuses and Foramen Magnum. A Master Thesis, Department of Oral and Maxillofacial Radiology, University of Baghdad; 2008. p. 33-40. 